\title{
Front Matter: Volume 10835
}

, "Front Matter: Volume 10835," Proc. SPIE 10835, Global Intelligence Industry Conference (GIIC 2018), 1083501 (31 August 2018); doi: $10.1117 / 12.2514318$

SPIE. Event: Global Intelligent Industry Conference 2018, 2018, Beijing, China 


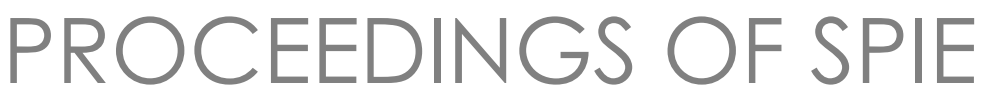

\title{
Global Intelligence Industry Conference (GIIC 2018)
}

\author{
Yueguang Lv \\ Editor
}

22-24, May 2018

Beijing, China

Organized by

Division of Information and Electronic Engineering of CAE (China)

Chinese Society for Optical Engineering (China)

Beijing Economic Technological Development Area (China)

Sponsored by

Chinese Academy of Engineering (China)

Published by

SPIE 
The papers in this volume were part of the technical conference cited on the cover and title page. Papers were selected and subject to review by the editors and conference program committee. Some conference presentations may not be available for publication. Additional papers and presentation recordings may be available online in the SPIE Digital Library at SPIEDigitalLibrary.org.

The papers reflect the work and thoughts of the authors and are published herein as submitted. The publisher is not responsible for the validity of the information or for any outcomes resulting from reliance thereon.

Please use the following format to cite material from these proceedings:

Author(s), "Title of Paper," in Global Intelligence Industry Conference (GIIC 2018), edited by Yueguang LV, Proceedings of SPIE Vol. 10835 (SPIE, Bellingham, WA, 2018) Seven-digit Article CID Number.

ISSN: 0277-786X

ISSN: 1996-756X (electronic)

ISBN: 9781510622999

ISBN: 9781510623002 (electronic)

Published by

SPIE

P.O. Box 10, Bellingham, Washington 98227-0010 USA

Telephone +1 3606763290 (Pacific Time) · Fax +1 3606471445

SPIE.org

Copyright (C) 2018, Society of Photo-Optical Instrumentation Engineers.

Copying of material in this book for internal or personal use, or for the internal or personal use of specific clients, beyond the fair use provisions granted by the U.S. Copyright Law is authorized by SPIE subject to payment of copying fees. The Transactional Reporting Service base fee for this volume is $\$ 18.00$ per article (or portion thereof), which should be paid directly to the Copyright Clearance Center (CCC), 222 Rosewood Drive, Danvers, MA 01923. Payment may also be made electronically through CCC Online at copyright.com. Other copying for republication, resale, advertising or promotion, or any form of systematic or multiple reproduction of any material in this book is prohibited except with permission in writing from the publisher. The CCC fee code is 0277 $786 \mathrm{X} / 18 / \$ 18.00$.

Printed in the United States of America.

Publication of record for individual papers is online in the SPIE Digital Library.

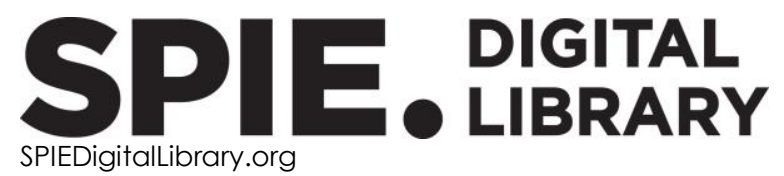

Paper Numbering: Proceedings of SPIE follow an e-First publication model. A unique citation identifier (CID) number is assigned to each article at the time of publication. Utilization of CIDs allows articles to be fully citable as soon as they are published online and connects the same identifier to all online and print versions of the publication. SPIE uses a seven-digit CID article numbering system structured as follows:

- The first five digits correspond to the SPIE volume number.

- The last two digits indicate publication order within the volume using a Base 36 numbering system employing both numerals and letters. These two-number sets start with 00, 01, 02, 03, 04, $05,06,07,08,09,0 A, 0 B \ldots$. OZ, followed by 10-1Z, 20-2Z, etc. The CID Number appears on each page of the manuscript. 


\title{
Contents
}

\author{
vii Authors \\ ix Conference Committee \\ xi Introduction
}

ARTIFICIAL INTELLIGENCE

1083502 Research and application of predictive function control based on adjustment coefficient [10835-1]

1083503 Contour detection using an improved holistically nested edge detection network [10835-2]

$1083504 \quad$ Biometric method to improve super resolution structure on Al and deep learning [10835-40]

1083506 Single-sample learning method and a type of brain activation function [10835-55]

$1083507 \quad$ Human action recognition using Kinect multimodal information [10835-66]

1083508 A survey of the application of deep learning in computer vision [10835-68]

1083509 Fault diagnosis for automotive assembly based on optical coordinate data and machine learning [10835-69]

10835 OA Violence detection based on three-stream convolutional networks [10835-72]

10835 OB Automatic human hallmark recognition based on visual words [10835-75]

INTELLIGENT MANUFACTURING

10835 OC Automatic measurement technology for equipment assembly accuracy of spacecraft AlT process [10835-3]

10835 OD Automatic measurement method of large scale satellite antenna in planar near-field test [10835-5]

10835 OE Research on aircraft digital shape measurement data fusion method [10835-6] 
10835 OF An error correction model based on neural network for laser displacement sensor [10835-23]

10835 OG Detection v-defect in $20^{\circ}$ wedge by laser ultrasound technique [10835-33]

$10835 \mathrm{OH} \quad$ Rotationally asymmetric figure measurement of optical flat using rotational shear phase measuring deflectometry [10835-38]

$10835 \mathrm{Ol} \quad$ A novel automated approach for noise detection in interference fringes pattern images using feature learning [10835-56]

10835 0J Vision system measuring remote target based on unmanned aerial vehicle [10835-57]

10835 OK Schlieren visualization of leaky guided waves in a liquid immersion plate [10835-60]

$10835 \mathrm{OL} \quad$ Delay time calculations for testing transverse defects of cylindrical surface artefacts with phased array ultrasonic [10835-63]

10835 OM Research on accelerated durability test of photovoltaic hollow modules [10835-64]

INTELLIGENT UNMANNED SYSTEMS

10835 ON UAV-based application for electromagnetic compatibility testing [10835-7]

$1083500 \quad$ Bathymetric data processing based on denoising autoencoder Wasserstein generative adversarial network [10835-9]

10835 OP Multi-sensor and multi-target task allocation method based on improved firefly algorithm [10835-11]

$108350 Q \quad$ Unmanned optical warning system for drones [10835-12]

10835 OR Free space propagation loss simulation analysis of aeronautical radio navigation station [10835-14]

10835 OS Research of image compression influence on SAR ATR based on an efficient CNN architecture [10835-17]

10835 OT Keyframe-based stereo visual-inertial SLAM using nonlinear optimization [10835-19]

10835 OU A brain computer interface control system based on cloud platform for Minitype UAVs [10835-20]

10835 OV Variable structure guidance with auto-generated impact angle constraint based on fuzzy strategy [10835-21]

10835 0X Research on the unmanned intelligent monitoring platform of geographical conditions [10835-24] 
10835 oY Influence of intelligent unmanned system on the development of intelligent measuring [10835-25]

$108350 Z$ An overview of SLAM [10835-26]

1083510 A MEMS random error analysis method fused with genetic algorithm [10835-27]

$1083511 \quad$ Research on recognition and tracking technology for a fully autonomous and agile response anti LLS-target system [10835-28]

1083512 A new approach for SAR baseband Doppler centroid estimation [10835-29]

1083513 An improved phase gradient autofocus approach for stripmap SAR imaging [10835-30]

1083514 Research on the modeling method of UAV swarm operation in cyberspace [10835-31]

1083515 Optimization simulation of aeromagnetic detection based on COMSOL multiphysics [10835-32]

$1083516 \quad$ Ground vehicles cooperative task area allocation for survivability improvement [10835-35]

1083517 Mission oriented self-organizing network methodology of UAV [10835-39]

1083519 Simulation-based analysis of bounding box localization algorithm for wireless sensor network [10835-43]

$108351 \mathrm{~A} \quad$ Research on intelligent target recognition technology for integrated reconnaissance/strike UAV [10835-44]

10835 1B Research and implementation of SAR simulator based on adaptive synchronization technology [10835-45]

10835 1C Research of adaptive error correction for multi-channel SAR receiver [10835-47]

10835 ID A fast Doppler beam sharpening approach based on short time FFT [10835-50]

$108351 \mathrm{E} \quad$ A high-resolution ground moving target imaging method based on motion compensation [10835-51]

$10835 \mathrm{IF} \quad$ Fast and high-accuracy systematic calibration of inertial devices based on IMU off-axis transposition [10835-52]

10835 IG Research on the fast calibration method of MEMS gyroscope [10835-53]

$108351 \mathrm{H} \quad$ Research on servitization based on UAV avionics system [10835-58]

$1083511 \quad$ First experimental results of the C band SAR and ground support system [10835-59] 
$108351 \mathrm{~J} \quad$ Target feature enhancement of SAR image based on discrete shearlet transform [10835-61]

10835 1K Research on the key technologies of unmanned cluster to sea combat [10835-62]

$10835 \mathrm{lL} \quad$ Operation method of electronic warfare UAV [10835-65]

10835 IM The UAV safety control based on cognition guidance [10835-67]

$108351 \mathrm{~N} \quad$ Summary of key technologies of combat intelligent unmanned aerial vehicle [10835-73]

1083510 The development of counter-unmanned aerial vehicle technologies [10835-74]

10835 IP Internal polyhedron configuration energy self-sufficient system for sphere mobile platform [10835-77]

$108351 Q \quad$ Research on key technologies of simulated training system for large ground control station of UAS [10835-78]

10835 is The Multi-UAV cooperative target tracking simulation system [10835-80] 


\section{Authors}

Numbers in the index correspond to the last two digits of the seven-digit citation identifier (CID) article numbering system used in Proceedings of SPIE. The first five digits reflect the volume number. Base 36 numbering is employed for the last two digits and indicates the order of articles within the volume. Numbers start with 00, 01, 02, 03, 04, 05, 06, 07, 08, 09, 0A, 0B...0Z, followed by 10-12, 20-2Z, etc.

Bian, Shaofeng, 00

Cai, Yefan, 01

Cao, Feng, 07

Cao, Ge, $1 \mathrm{C}$

Chai, Liqun, OF

Chang, Zheng, 03

Chen, Chang, OT

Chen, Wei, OB

Chen, Xiaocen, $1 \mathrm{~F}$

Chen, Yangyi, 15

Chen, Yazhou, ON

Chen, Yongbing, 00

Cheng, Yunfei, 08, OA

Cheng, Erwei, ON

Cheng, Haoyu, 1M

Cheng, Qian, OK

Dai, Ning, IP

Ding, Quanxin, 04

Dong, Liang-ci, OV

Dong, Shiyun, 06

Du, Junlin, OY

E., Kewei, $\mathrm{OH}$

Fu, Jun, 10, $1 \mathrm{G}$

Gao, Duanyang, 00, 10, $1 \mathrm{G}$

Gu, Hairui, 10

Gu, Tao, 17

Guan, Lili, OF

Guo, Chunjie, 04

Guo, Fang, $0 J$

Guo, Hongcao, OX

Guo, Jundong, $1 \mathrm{C}$

GUO, Li Li, OE

Guo, Xiaojun, 15, 19

Guo, Zheng, 1B, 1C

Guo, Zijia, 11

Han, Guoqing, $0 Q$

Han, Hongxiang, $1 G$

Han, Qing-bang, OG, OK, OL

Han, Song, OS, $1 \mathrm{~B}$

$\mathrm{He}$, Yuhang, OF

$\mathrm{Hu}$, Chun-ling, 07

$\mathrm{Hu}$, Jian-Gen, 02

Hu, JianMin, 1 I

$\mathrm{Hu}$, Ruiqin, $\mathrm{OC}$

$\mathrm{Hu}$, Shuhong, IP

Huang, Hanqiao, 1M

Hui, Bin, 03

Jia, Jing, OG, OK, OL

Jia, Lili, OB
Jiang, Huanhuan, 1A

Jiang, Kai, $1 \mathrm{~A}$

Jiang, Xue-ping, OK, OL

Jin, Bo, OZ

Jing, Xueping, OG

Kang, Minyang, $1 \mathrm{H}$

Lan, Weiqi, OT

Li, An, 10

Li, Bingfei, $1 \mathrm{~K}$

$\mathrm{Li}$, Dahai, $\mathrm{OH}$

Li, Ge, IP

$\mathrm{Li}$, Jing, $\mathrm{OH}$

$\mathrm{Li}, \mathrm{Kun}, \mathrm{OH}$

Li, Qiang, OF

Li, Quan, 02

Li, Wei, 07

Li, Xinyi, IP

Li, Yuankai, OR

Lian, Guofu, OJ

Liang, Fei, $O R$

Liang, Jinbo, 01

Liu, Bidan, 12, 13, $1 \mathrm{E}$

Liv, Chang, 12, 13, 1D, $1 \mathrm{E}$

Liv, Changhua, 1Q

Liu, Hong, $1 Q$

Liu, Hua, 04

Liu, Jingyu, 11

Liu, Keya, 11

Liu, Qi, OE

Liv, Shangkuo, $\mathrm{OH}$

Liu, Wenbin, OB

Liv, Xiao, OD

Liu, Yu Song, OE

Liu, Yuexia, 08, 0A

Long, Changyu, OC, OD

Long, Teng, 16

Lu, Hongbo, $1 \mathrm{P}$

Luo, Haibo, 03

Luo, Zhi-Hao, $\mathrm{O2}$

Man, Keshuang, OA

Miao, Jisong, $1 \mathrm{~F}$

Pan, Jeng-Shyang, OJ

Pan, Zhigang, $1 \mathrm{~J}$

Pan, Zhuo, 11, 1J

Qian, Ziqing, 1P

Qin, Xuebin, OU

Ren, Yuan, $1 \mathrm{~F}$

Ruan, Guowei, OD

Shang, Wei, OV 
Shao, Qiongling, If

Si, Guangya, 14

Song, Qiudong, $0 Q$

Su, Long, $1 \mathrm{~A}$

Su, Shaojing, 15, 19

Su, Ye, 02

Sui, Xin, $1 \mathrm{~N}$

Sun, Xiaoyong, 15

Tan, Junyang, 06

Tang, Chao, 07

Tang, Kai, OX, OY

TaO, Li, OD

Wan, Daoming, OF

Wang, Xiao-feng, 07

Wang, Chao, 1D, 1E

Wang, Chen, IF

Wang, Chunjie, OS

Wang, Dawei, $1 \mathrm{~N}, 10$

Wang, Dong, OM

Wang, Gang, OU

Wang, Helong, 04

Wang, Kexiang, 17

Wang, Lei, OT

Wang, Li, OM

Wang, Mei, OU

Wang, Pei, is

Wang, Pengxiang, OP

Wang, Qi, 13, 1D, 1E

Wang, Shengyin, 16

Wang, Shuo, $1 \mathrm{H}$

Wang, Wu, 08, 0A

Wang, Xiao-feng, 07

Wang, Yanfei, OS, 12, 13, 1B, 1C, 1D, 1E, 1I, 1J

Wang, Yanzheng, 14

Wang, Yibo, $1 \mathrm{~N}$

Wang, Yunhui, $1 \mathrm{H}, 1 \mathrm{~L}$

Wang, Zhengfeng, $\mathrm{OH}$

Wang, Zhi Hai, OE

Wang, Zhu, 16

Wu, Chao, is

Wu, Peng, 19

Wu, Tao, $1 \mathrm{~A}$

Xia, Dan, 06

Xiong, Jun-hui, OV

Xu, Binshi, 06

$X U$, Guangtong, 16

$X U$, Jian, OR

$\mathrm{XU}$, Zheng, 03, OK

Xue, Bing, $1 \mathrm{H}, 1 \mathrm{~L}$

Xue, Xun, $\mathrm{OH}$

Yang, Baichun, 10

Yang, Feng, $\mathrm{OP}, \mathrm{OZ}$

Yang, Kai, 10

Yang, Kun, $1 \mathrm{~N}$

Yao, Zhao, IN

Ye, Pingfan, $O R$

Yi, Wangmin, OC, OD

Yin, Feng, 02

Yin, Zongdi, $O Q$

Yu, Xiangyang, OI
Yue, Yun-fei, OL

Zeng, Xuan, 09

Zhan, Xueli, 1D, 1I, 1J

Zhan, Zhijuan, 1H, 1K, 1L

Zhang, Bing, OX, OY

Zhang, Dongxiao, ON

Zhang, Lei, 10

Zhang, Lin, OU

Zhang, Litao, OP

Zhang, Miao-hui, 07

Zhang, Qi, 1 I

Zhang, Ruichen, 00, 10

Zhang, Wei, $1 \mathrm{P}$

Zhang, Wenqi, 10

Zhang, Yang, 14

Zhang, Yizhai, OP

Zhao, Jianke, $\mathrm{OH}$

Zhao, Tao, OV

Zheng, Litao, OP

Zheng, Meiyun, $1 \mathrm{M}$

Zheng, Xueli, 17

Zhou, Huan, $1 \mathrm{M}$

Zhou, Liwei, 04

Zhou, Qing, 1K

Zhou, Wei, is

Zhou, Xun, IN

Zhou, Yan, $\mathrm{OH}$

Zhu, Honghao, 06

Zhu, Hua, OT

Zhu, Meng, OQ

Zhu, Yong, 16 


\title{
Conference Committee
}

\author{
Conference Chairs
}

Ji Zhou, Chinese Academy of Engineering (China)

Guozhi Liu, Chinese Academy of Sciences (China)

Zuoning Chen, Chinese Academy of Engineering (China)

Huettl Reinhart, Deutsche Akademie der Technikwissenschaften

(Germany)

Yunhe Pan, Chinese Academy of Sciences (China)

Hequan Wu, Chinese Academy of Sciences (China)

Guofan Jin, Tsinghua University (China)

Guangjun Zhang, Southeast University (China)

Yueguang Lv, Chinese Academy of Engineering (China)

Xiangli Bin, Chinese Academy of Sciences (China)

John Dewar, LaTrobe University (Australia)

Lin Li, University of Manchester (United Kingdom)

Magnus Breidne, Royal Swedish Academy of Engineering Science (Sweden)

Min Gu, RMIT University (Australia)

Shi-wan Lin, American Industrial Internet Alliance (United States)

Technical Committee

Wen Gao, Peking University (China)

Nanning Zheng, Xi'an Jiaotong University (China)

Weimin Bao, China Aerospace Science and Technology Corporation (China)

Zuyan Xu, Technical Institute of Physics and Chemistry, CAS (China)

Songlin Zhuang, Shanghai University of Science and Technology (China)

Tianyou Chai, Northeastern University (China)

Deyi Li, Institute of China Electronic System Engineering (China)

Bohu Li, China Aerospace Science and Industry Corporation Ltd. (China)

Chun Chen, Zhejiang University (China)

Tianran Wang, Shenyang Institute of Automation, CAS (China)

Jianquan Yao, Tianjin University (China)

Junhao Chu, Shanghai Institute of Technical Physics, CAS (China)

Cheng Wu, Tsinghua University (China)

Manqing Wu, China Electronics Technology Group Corporation (China)

Jiancheng Fang, Beihang University (China)

You Zheng, Tsinghua University (China)

Ru Huang, Peking University (China)

Wei Huang, Northwestern Polytechnical University (China)

Wei Wang, China Aerospace Science and Technology Corporation (China) 
Huaming Wang, Beihang University (China)

Lijun Wang, Changchun Institute of Optics, Precision Mechanics, and Physics, CAS (China)

Bangkui Fan, Beijing Institute of Information Technology (China) Qionghai Dai, Tsinghua University (China) 


\section{Introduction}

We had the great honor of organizing the Global Intelligent Industry Conference 2018. It was a great pleasure for us to greet the more than 2000 participants from many different countries attended. We firmly believe this conference will become an important international event in the field of Al technology.

The Global Intelligent Industry Conference 2018 was sponsored by the Chinese Academy of Engineering and was organized by the Division of Information and Electronic Engineering of CAE, Chinese Society for Optical Engineering, Beijing Economic Technological Development Area.

The purpose of this conference is to provide a forum for the participants to report and review innovative ideas and up-to-date progress and developments and discuss novel approaches to application in the Al field. It is sincerely hoped that the research and development in the Al field will be promoted, and international cooperation sharing the common interest will be enhanced.

On behalf of other co-chairmen, and the organization committee, we would like to thank our sponsors and cooperation organizers for all they have done for this conference. Thanks also to all the authors for their contributions to the proceedings, to all of the participants and friends for their interest and efforts in helping us to make this conference possible, to the program committee members for their effective work and valuable advice, and to the secretariat and SPIE staff for their tireless efforts and outstanding service in preparing and publishing the proceedings.

Yueguang LV 
Proc. of SPIE Vol. 10835 1083501-12 Downloaded From: https://www.spiedigitallibrary.org/conference-proceedings-of-spie on 26 Apr 2023
Terms of Use: https://www.spiedigitallibrary.org/terms-of-use 